\title{
Editorial
}

\section{Identifying tax norms}

\author{
Paul R. McDaniel, Hill \& Barlow, Boston
}

The changes in the global economic position of the United States that have taken place over the past decades inevitably have produced calls from some quarters that the US system of international taxation is archaic and needs to be replaced or significantly modified if US companies are to be able to compete effectively in world markets. One of the assertions that is used to support that contention is that the US needs to conform its tax rules to 'international norms' or, in a more limited sense, to the 'norms' of the principle trading partners of the US.

It is not my purpose here to consider whether any particular tax changes might improve the competitiveness of US corporations in international markets. I am interested in the issues raised by the resort to 'international norms' as a justification for the proposed changes. All who have been involved in the international tax field have heard this phrase used in a number of different contexts. For example, in the debate about the adoption of full-blown unitary tax systems by some states in the US, it was often asserted, and correctly, that the arm's length transfer pricing method was the 'international norm', at least in dealings involving only developed countries. And so when the phrase is used again, there is a tendency for us to nod affirmatively as if we know what that phrase means. But the more I considered the matter, the less sure I was that I know what is being asserted by speakers and writers who currently use the phrase in discussing international tax policy issues, regardless of the particular country from which they speak. In the following discussion, I draw primarily on examples from the US experience but, if I am correct, readers should be able to apply the concepts to their own tax systems.

First, consider the assertion by some that the US should change from a foreign tax credit system to an exemption system because the latter is the 'international norm' or, less sweepingly, is the norm of our principal trading partners. It is certainly true that a country can adopt one or the other of the two systems, depending on various objectives the country may seek to achieve. But is it true that the exemption system is the 'norm' in either sense of the term? My own unscientific view is that the trend in so-called exemption countries over the past several years has been toward expanding the use of the foreign tax credit mechanism (certainly in the case of investment income), both by unilateral statutory action and by bilateral treaty agreements with foreign tax credit counties such as the US. Note, for example, the provision in the recently ratified US-Germany tax treaty under which Germany switches from an exemption approach to a credit approach in cases involving conflicting classification of income items. If I am correct in this assertion, the 'international norm' may be moving in the direction of the foreign tax credit mechanism and away from the exemption system and, in any event, the movement clearly is not unambiguously in one direction. (I also hasten to add the obvious: it makes a great deal of difference which countries one decides to include in identifying the 'international norm'.) In identifying an international norm, the trend may be more critical than a snapshot of legislative provisions that may exist at a particular point in time.

Others have asserted that the US should adopt particularized changes in its tax system to bring the US into line with an asserted international norm. Candidates for such changes include the US rule for allocation of interest deductions, reducing the number of 'baskets' for foreign tax credit purposes (e.g., investment and active business income, high tax and low tax income), and reducing the scope of subpart $\mathrm{F}$ to permit greater deferral of US tax on foreign source income.

Any of the proposed changes must be closely analyzed to determine if the resort to an asserted international norm, in fact, supports the change. Take, for example, the allocation of interest deduction issue. It is asserted by some that the extremely sophisticated (and therefore complex) rules in the US should be brought into conformity with international norms by allowing a US multinational company to deduct its interest expense entirely against 
US source income. They point to the fact that certain other countries permit this result and hence the US should conform to this alleged 'international norm'. But the important question is why does a given country not require a more sophisticated allocation. One answer may be, for example, that a given exemption country may not yet have recognized that it must have an allocation system if it is to apply the necessary rule that disallows deductions for costs of producing exempt income. But this may be a transitional situation, not a normative decision. Another country may have moved somewhat beyond the first by imposing a tracing requirement for interest expense deduction allocation purposes. And such a rule may work in some countries where the tax 'culture' does not push such a rule to its limits. But in a country like the US, an aggressive tax bar and accounting professionals will ensure that a tracing rule imposes no limit at all on the ability of a US company to deduct virtually all of its interest expense against US income. Still a third exemption country may have examined the interest allocation issue, determined that its normative rules would require allocation of part of a company's interest expense to exempt income and then decide quite consciously not to require such an allocation because it wants to provide financial incentives or assistance for its companies to carry on business abroad. (Here we enter the area of tax subsidies to which we turn below.) The point is that, in my view, it is quite impossible to assert that there is an international norm that interest costs should be entirely deductible in the home country without a clear understanding of why the country utilizes the particular rule it has adopted.

There is third category of provisions which must be clearly identified in asserting the existence of an international norm. It is well recognized that governments provide financial incentives and cost-sharing subsidies through their tax systems. As noted above, in some countries the decision not to adopt effective interest deduction allocation rules may constitute such a provision. More clearly, a provision in an exemption system allowing a deduction against domestic income for foreign losses or a provision in a foreign tax credit system permitting exemption of foreign source income each constitutes a subsidy administered through the tax system. Obviously, such provisions cannot be resorted to in order to assert an international 'tax' norm (and it seems unlikely that there is an international 'subsidy norm').

To sum up: There is a role for normative analysis of international tax rules. Such an analysis is appropriate for example, in testing particular provisions in a country that has decided it wishes to employ either a thoroughly developed exemption or foreign tax credit approach. But tax policy analysts can mislead themselves and tax policymakers by taking a snapshot of the nominal provisions of selected countries' legislation to find a norm. Careful analysis must be made to determine what truly constitutes a particular country's normative position, whether that position is in the process of changing, whether one country's nominal legislation could be abused if adopted by another country, and the actual role that the provisions under examination play in a country's total tax system. 